\title{
TOLERÂNCIA AO RISCO DE GESTORES: ANÁLISE NA TOMADA DE DECISÕES NOS CAMPOS PESSOAL E ORGANIZACIONAL ${ }^{1}$
}

\section{MANAGER RISK TOLERANCE: ANALYSIS IN DECISION-MAKING IN PERSONAL AND OR- GANIZATIONAL FIELDS}

\author{
Ernando Fagundes \\ Doutorando em Ciências Contábeis (UFSC) \\ Universidade Federal de Santa Catarina \\ fagundes.ernando@gmail.com \\ Darci Schnorrenberger \\ Doutor em Engenharia de Produção (UFSC) \\ Universidade Federal de Santa Catarina \\ darcisc@gmail.com \\ Valdirene Gasparetto \\ Doutora em Engenharia de Produção (UFSC) \\ Universidade Federal de Santa Catarina \\ valdirenegasparetto@gmail.com \\ Rogério João Lunkes \\ Doutor em Engenharia de Produção (UFSC) \\ Universidade Federal de Santa Catarina \\ rogeriolunkes@hotmail.com
}

\section{RESUMO}

Objetivo: Analisar se o campo da decisão (pessoal ou organizacional) influencia na tolerância ao risco de gestores.

Fundamento: O estudo é realizado à luz da Teoria do Prospecto (Kahneman \& Tversky, 1979).

Método: Foi realizado um experimento de campo com 236 gestores de organizações que responderam um questionário com decisões envolvendo riscos, a partir das quais deveriam optar por uma das duas alternativas apresentadas. $\mathrm{O}$ tratamento realizado na variável de interesse (campo de decisão) ocorreu por meio da alteração das situações apresentadas aos gestores de cada grupo, mantendo o montante e probabilidade de ocorrência de ganhos e perdas de cada situação.

Resultados: Os resultados indicaram que tomar decisões no campo organizacional influencia na tolerância ao risco do decisor. Em situações envolvendo ganhos, os gestores submetidos a decisões organizacionais foram menos tolerantes ao risco do que os submetidos a decisões pessoais. Já na

\footnotetext{
${ }^{1}$ Artigo recebido em: 20/12/2019. Revisado por pares em: 06/08/2020. Reformulado em: 18/11/2020. Recomendado para publicação: 14/01/2021 por Karla Katiúscia Nóbrega de Almeida (Editora Adjunta). Publicado em: 11/02/2021. Organização responsável pelo periódico: UFPB
} 
perspectiva de perdas, os gestores que tomaram decisões no campo organizacional foram mais tolerantes ao risco, comparativamente aos que tomaram decisões no campo pessoal.

Contribuições: Os achados ampliam o conhecimento acerca da tolerância ao risco, visto que apresentam o campo de decisão como fator que influencia o comportamento de gestores na tomada de decisão. O estudo contribui com a literatura sobre tolerância ao risco e suas alterações a partir da abordagem comparativa do campo no qual as decisões são tomadas - pessoal e organizacional.

Palavras-chave: Campo de decisões. Teoria do Prospecto. Tolerância ao risco. Decisões pessoais e organizacionais.

\section{ABSTRACT \\ Objective: Analyze whether the decision field (personal or organizational) influences the risk tol- erance of managers.}

Background: The study is conducted in light of Prospect Theory (Kahneman \& Tversky, 1979).

Method: A field experiment was conducted with 236 managers of organizations who answered a questionnaire with risk decisions, from which they should choose one of the two alternatives presented. The treatment performed in the variable of interest (decision field) occurred by changing the situations presented to the managers of each group, keeping the amount and probability of occurrence of gains and losses of each situation.

Results: The results indicated that making decisions in the organizational field influences the risk tolerance of the decision maker. In earnings situations, managers subjected to organizational decisions were less risk tolerant than those subjected to personal decisions. From the perspective of losses, managers who made decisions in the organizational field were more risk tolerant compared to those who made decisions in the personal field.

Contributions: The findings increase the knowledge about risk tolerance, since they present the decision field as a factor that influences the behavior of managers in decision making. The study contributes to the literature on risk tolerance and its changes from the comparative approach of the field in which decisions are made - personal and organizational.

Keywords: Decision field. Prospect Theory. Risk tolerance. Personal and organizational decisions

\section{INTRODUÇÃO}

Tomar decisões é intrínseco à natureza humana e decisões acontecem nos campos pessoal e organizacional, nas situações em que existem alternativas de escolha na busca pelo alcance de um objetivo (Hammond, Keeney \& Raiffa, 2017). Das decisões do campo pessoal para o organizacional, mudam a complexidade, frequência e amplitude das consequências. Mesmo assim, não raras vezes, os decisores carecem de suporte informacional, o que acaba impactando nos resultados (Leonard, Scholl \& Kowalski, 1999; Solino \& El-Aouar, 2010). Tomar decisões constitui-se numa das principais atribuições dos gestores, e uma decisão errada pode afetar de maneira irreversível a organização (Hammond, Keeney \& Raiffa, 1998).

Modelos para a tomada de decisões racionais têm sido propostos e amplamente aceitos ao longo do tempo, porém, em grande parte, ignoram a influência de valores, experiências vividas e características individuais dos decisores (Leonard, Scholl \& Kowalski, 1999; Shepherd, Williams \& Patzelt, 2015), além de não considerarem a tolerância ao risco dos indivíduos. Segundo Hammond, Keeney e Raiffa (1999), a tolerância ao risco de um indivíduo é tão específica quanto a própria personalidade, fazendo com que alguns o evitem enquanto outros o buscam. 
Chen, Sim, Simchi-Levi e Sun (2007) afirmam que a modelagem de decisões sensíveis ao risco é um dos problemas fundamentais em economia. Fagundes, Schnorrenberger e Lunkes (2018) observam que no cenário internacional, a pesquisa acerca do comportamento dos indivíduos no momento da tomada de decisões tem despertado interesse dos pesquisadores e evoluído nos últimos anos. No entanto, os estudos ainda são fragmentados e as conclusões dificultam o posicionamento do estágio em que se encontram (Shepherd, Williams \& Patzelt, 2015).

No Brasil, estudos sobre o comportamento dos indivíduos na tomada de decisões têm sido realizados (Luppe \& Angelo, 2010; Lucena, Gomes, Ferreira \& Lucena, 2011; Lima Filho \& Bruni, 2013; Nobre, Macedo, Nobre \& Silva, 2017; Lobel, Klotzle, Silva \& Pinto, 2018; Bilk, Barbosa, Silva \& Nakamura, 2018; Gava \& Vieira, 2008) e, de modo geral, as pesquisas têm replicado o estudo de Kahneman e Tversly (1979), não investigando aspectos adicionais (Oliveira \& Krauter, 2015; Ross, Nora \& Milani, 2015). Alguns desses estudos nacionais analisaram a tolerância ao risco de acadêmicos e profissionais atuários (Bilk et al., 2018) ou ainda, buscaram determinar fatores relacionados à tolerância ao risco - idade, estado civil, renda e gênero - (Nobre et al., 2017; Lobel et al., 2018; Gava \& Vieira, 2008). No entanto, observa-se que estes estudos têm adotado instrumentos com decisões tomadas diante de situações apenas relacionado ao campo pessoal, e desconsideram os diferentes campos de tomada de decisão, como o pessoal e o organizacional.

Além das situações decisionais que afetam mais diretamente quem decide, há situações em que as pessoas decidem por terceiros. Verificar a capacidade de julgamento sobre tolerância ao risco de outras pessoas, bem como avaliar se os riscos são aceitáveis, constitui-se numa questão crítica nos estudos de tomada de decisões (Harvey, Twyman \& Harries, 2006). No ambiente organizacional, cada vez que um gestor toma decisões pela organização, está escolhendo uma alternativa dentre outras, sendo que suas crenças e convicções influenciarão na escolha. Suas decisões trarão consequências diretas à organização e indiretas ao gestor. Por outro lado, decisões tomadas no campo pessoal trarão consequências diretas para o indivíduo e indiretas para as pessoas à sua volta.

De acordo com Reynolds, Joseph e Sherwood (2009), a tolerância ao risco de um indivíduo pode mudar conforme as diferenças de ambientes, como ambientes de grupos ou ambientes organizacionais, por exemplo. Assim, parece que, à medida que os indivíduos adquirem responsabilidade em decidir por outros indivíduos, eles podem exibir uma mudança cautelosa e isso pode afetar a tomada de decisões de negócios.

A literatura sobre tolerância ao risco se concentra principalmente em decisões no campo pessoal, enquanto estudos e discussões acerca de risco em decisões organizacionais ainda não se encontram tão explorados (Fagundes, Schnorrenberger \& Lunkes, 2018). E ainda, os resultados das pesquisas acerca da tomada de decisões por terceiros não são convergentes (Andersson, Holm, Tyran \& Wengström, 2014). Assim, no intuito de avaliar se o campo da decisão (pessoal ou organizacional) influencia na tolerância ao risco, emerge a seguinte questão de pesquisa: o campo em que a decisão é tomada influencia na tolerância ao risco de quem está decidindo? O trabalho tem como objetivo analisar se o campo da decisão (pessoal ou organizacional) influencia na tolerância ao risco de gestores. Para tanto, realizou-se um experimento de campo com gestores no Estado de Santa Catarina.

Entender as alterações na tolerância ao risco dos indivíduos a partir do campo no qual a decisão é tomada contribui para compreender o processo de tomada de decisões, bem como os fatores que o influenciam (Simon et al., 1987). A tolerância ao risco é fator que influencia decisões econômicas (Melesse \& Cecchi, 2017), havendo evidências da necessidade de estudos que busquem verificá-la quando envolve decisões tomadas por outros (Andersson et al., 2014; Fagundes, Schnorrenberger \& Lunkes, 2018), como é o caso de decisões tomadas por gestores em organizações. 
Como resultados deste estudo espera-se prover suporte para melhor compreender as nuances envolvidas na tomada de decisões em ambientes cada vez mais complexos e dinâmicos, cujas consequências podem alçar a organização ao êxito ou colocá-la em situação delicada. Assim, conhecendo melhor as preferências dos decisores, esses desafios podem ser superados e constituírem-se em oportunidades e vantagem competitiva, resultando em decisões mais assertivas do que as dos concorrentes (Russo \& Schoemaker, 2002).

O estudo também pretende contribuir com a literatura sobre tolerância ao risco e suas alterações a partir da abordagem comparativa do campo no qual as decisões são tomadas - pessoal e organizacional. Luppe e Angelo (2010), Lima Filho e Bruni (2013) e Souza (2017) destacam que, no Brasil, o comportamento dos indivíduos no processo de tomada de decisões é considerado um tema emergente. Salterio (2015) e Shields (2015) afirmam que se trata de uma área do conhecimento com interesse emergente, principalmente quando aplicada à contabilidade gerencial.

\section{FUNDAMENTAÇÃO TEÓRICA E DESENVOLVIMENTO DE HIPÓTESES}

\subsection{Tolerância ao risco e Teoria do Prospecto}

O risco está relacionando a opção de um indivíduo, diante de uma decisão, em optar por correr ou não esse risco (Rodrigues e Veloso, 2013). Assim, a tolerância ao risco é um conceito que descreve o que um indivíduo faz quando confrontado com uma opção arriscada e outra mais segura (Hsee \& Weber, 1997). Assim, a tomada de decisões sob risco pode ser vista como uma escolha entre perspectivas. Tem-se a escolha $x$ com possibilidade $p$, e a escolha y com possibilidade $1-p$. Uma pessoa é menos tolerante ao risco se preferir a perspectiva menos arriscada à mais arriscada com valor esperado $x$. A escolha do indivíduo ante uma situação é um preditor do seu comportamento em relação à sua tolerância ao risco (Hsee \& Weber, 1997).

A Teoria da Utilidade Esperada (Expected Utility Theory) ou TUE dominou a tomada de decisões sob risco, tendo sido aceita como um modelo normativo de escolha racional, e amplamente aplicada como modelo normativo do comportamento econômico. No entanto, Kahneman e Tversky (1979) apresentaram problemas de escolhas, nos quais os participantes violaram sistematicamente os axiomas da TUE, indicando fragilidade da teoria em captar adequadamente as decisões envolvendo risco. Para Kahneman (2012), uma das principais fragilidades da TUE é assumir o pressuposto de que a utilidade percebida para situações envolvendo ganhos ou perdas são iguais.

Em pesquisas sobre risco, no campo pessoal, Kahneman e Tversky (1979) apresentaram aos entrevistados problemas do tipo: qual das opções você prefere? A: $50 \%$ de chance de ganhar \$ 1.000 e $50 \%$ de chance de não ganhar nada; ou B: ganhar $\$ 450$ com $100 \%$ de certeza. Na análise dos dados constataram que, diferentemente do que preconizava a TUE, a função valor era definida por desvios do ponto de referência (status quo), tendo como característica o fato de que é geralmente côncava para ganhos e convexa para perdas, sendo mais acentuada nas perdas do que nos ganhos (Kahneman \& Tversky, 1979; Tversky \& Kahneman, 1991). Uma função valor que satisfaz essas propriedades é exibida na Figura 1. 


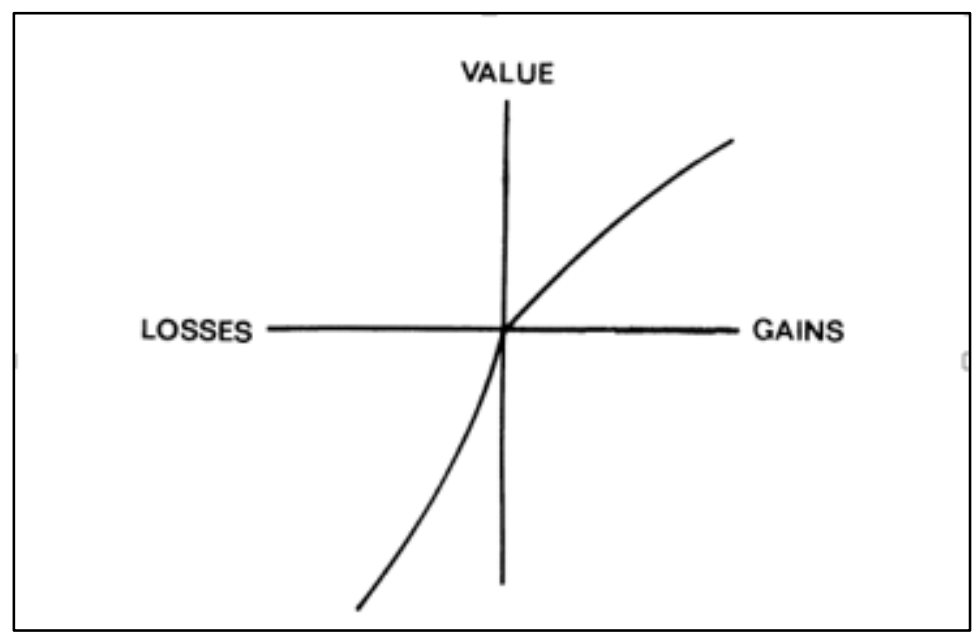

Figura 1. Função Valor da Teoria do Prospecto (TP)

Fonte: Kahneman \& Tversky (1979).

A partir desses experimentos, Kahneman e Tversky (1979) apresentaram a Teoria do Prospecto (Prospect Theory) ou TP, que consiste em um contraponto à TUE como modelo descritivo para a tomada de decisões. De acordo com a TP, quando se comparam direta e proporcionalmente as perdas em relação aos ganhos, as perdas assomam como maiores do que os ganhos (Kahneman, 2012). Ou seja, de modo geral, as pessoas buscam o risco quando confrontadas com possibilidades de perdas, mas o evitam no domínio dos ganhos (Zaleskiewicz, 2001; Abdellaoui, Bleichrodt \& Kammoun, 2013; Talpsepp, Vlcek \& Wan, 2014). Essa relação, de acordo com Kahneman e Tversky (1979), Kahneman, Knetsch e Thaler (1990) e Tversky e Kahneman (1991), costuma ser de aproximadamente 2 para 1.

Algumas generalizações são possíveis a partir da TP, enquanto outras requerem maior desenvolvimento. A fim de abranger uma gama mais ampla de problemas de decisão, a TP deve ser estendida em várias direções (Kahneman \& Tversky, 1979).

\subsection{Fatores que influenciam a tolerância ao risco}

A tolerância ao risco varia de acordo com as características do decisor e do ambiente: demográfico, psicológico, financeiro e comportamental (Geetha \& Selvakumar, 2016). É recomendado que estudos sobre tomada de decisões incorporem as diferenças de comportamentos e sua influência nas escolhas (Ramiah, Zhao, Moosa \& Graham, 2016).

O estudo no qual Kahneman e Tversky (1979) apresentaram a TP, foi desenvolvido no campo de escolhas pessoais. Grande parte dos estudos seguintes usaram esse mesmo tipo de decisão, ou seja, situações que envolvem decisões do campo pessoal. Porém, Vlaev, Stewart e Chater (2008) afirmam que a tolerância ao risco não é estável, mas influenciada pelo contexto, de modo que são avaliadas perspectivas, relacionando-as umas com outras.

A tomada decisão envolve, muitas vezes, escolhas que afetam não apenas o próprio decisor, mas também outras pessoas pelas quais o decisor está tomando a decisão (Pahlke, Strasser \& Vieider, 2015). Montinari e Rancan (2013) complementam afirmando que muitas vezes as pessoas tomam decisões por outras, como colegas, empregados, clientes, acionistas, cônjuges e crianças. Andersson et al. (2014) complementam que as decisões pelos outros também estão presentes em comportamentos relacionados a gestão, investimentos financeiros e contratação. Como exemplo, citam a crise financeira de 2008, em que os atores do setor financeiro foram acusados de assumir riscos excessivos em nome de outros, tendo estimulado um grande debate público.

No campo organizacional, situações onde as pessoas decidem por outras envolvem aquelas em que gestores administram o dinheiro de outros: um Chief Executive Officer (CEO) que toma de- 
cisões em nome dos conselhos e acionistas, gestores que delegam decisões aos funcionários e assim por diante.

Apesar da extensa literatura sobre tomada de decisões individuais sob risco e incerteza, há menos evidências quando o decisor está decidindo por outras pessoas (Eriksen \& Kvaløy, 2009; Andersson et al., 2014; Kvaløy \& Luzuriaga, 2014; Pahlke, Strasser \& Vieider, 2015). Além disso os resultados não são convergentes (Andersson et al., 2014; Pahlke, Strasser \& Vieider, 2015), variando de aumento da aversão ao risco para maior procura de risco ou resultados nulos (Pahlke, Strasser \& Vieider, 2015).

Montinari e Rancan (2013) descobriram que, ao decidir em nome de terceiros, apesar de todo o resto ser igual, os indivíduos fazem escolhas diferentes do que quando decidem apenas por si mesmos. Estas escolhas feitas em nome de outros parecem afetadas por considerações altruístas, moduladas pela distância social entre o decisor e o afetado pelas consequências das decisões.

Considerando que as decisões sob responsabilidade, ou seja, quando o indivíduo decide por outra pessoa, podem diferir das decisões individuais, os achados dos estudos realizados no campo de decisões individuais constituirão preditores imperfeitos de atitudes sob responsabilidade ou, ainda, de decisões no campo organizacional (Pahlke, Strasser \& Vieider, 2015). Nesse sentido, Chakravarty, Harrison, Haruvy e Rutström (2011) pesquisaram se a tolerância ao risco é refletida quando o indivíduo toma decisões que afetam outros, como na estrutura corporativa típica. No entanto os autores examinaram essas atitudes de risco pelos outros por meio de decisões que envolviam situações genéricas, não simulando situações rotineiras de uma organização.

Reynolds, Joseph e Sherwood (2009) afirmam que as pessoas são mais tolerantes ao risco ao tomar decisões por si mesmas e menos tolerantes na tomada de decisões que afetam terceiros. Isso indica que as pessoas exibem uma mudança cautelosa. $\mathrm{O}$ experimento foi realizado com alunos, devendo-se verificar se essas evidências de comportamento menos tolerante ao risco relativamente maior para o benefício de outros ocorre no mundo real.

Pahlke, Strasser e Vieider (2015) afirmam que na perspectiva de ganhos, tomar decisões por outros diminui a tolerância ao risco do indivíduo. Na perspectiva de perdas, os decisores que estão decidindo por outros buscam com maior intensidade o risco do que quando decidem por si próprios. Assim, a justificativa da adoção de maior cautela quando decidem por outros é possível na perspectiva de ganhos, mas é violada no domínio das perdas.

Os resultados de Chakravarty et al. (2011) apontam que os indivíduos tendem a ser significativamente mais tolerantes ao risco quando tomam decisões para outra pessoa, quando comparadas com as decisões que tomam para si próprios. Se o principal e o agente não tiverem tolerância ao risco semelhante, no sentido de que o agente não exibe a mesma tolerância ao risco do principal ao agir em seu nome, existe uma perda de eficiência esperada se eles não usarem contratos elaborados. No entanto, há necessidade de melhor compreensão das motivações para os indivíduos que agem em nome de outros.

Hsee e Weber (1997) aplicaram três experimentos que revelaram um viés sistemático: os participantes previam que os outros buscavam mais riscos do que eles em escolhas arriscadas, independentemente de as escolhas serem entre opções com resultados negativos ou positivos. Verificaram ainda que os participantes eram muito limitados em predizer a tolerância ao risco dos outros, de modo que superestimavam a propensão de terceiros em correr riscos, tanto para ganhos quanto para perdas. Porém, constataram que essa discrepância desaparecia quando previam riscos para terceiros que estavam presentes no experimento.

Schultz, Robinson, Thomas, Schultz e McClain (2018) destacam que o campo no qual se está tomando a decisão influencia no comportamento dos decisores diante de decisões sob risco. Nesse sentido, He e Villeval (2017) destacam que não está claro se as diferenças na tolerância ao risco são 
mais fortes ou mais fracas em um ambiente organizacional quando comparado a um ambiente individual ou pessoal.

De acordo com Reynolds, Joseph e Sherwood (2009), a literatura apresenta que o nível normal de risco de uma pessoa muda quando ela muda de ambiente, como por exemplo, o organizacional. À medida que os indivíduos adquirem responsabilidades, se percebe uma mudança cautelosa e isso pode afetar a tomada de decisões organizacionais. A partir dos apontamentos da literatura são formuladas as seguintes hipóteses de pesquisa:

H1: Na perspectiva de ganhos, os gestores são menos tolerantes ao risco na tomada de decisões no campo organizacional do que no campo pessoal.

H2: Na perspectiva de perdas, os gestores são mais tolerantes ao risco na tomada de decisões no campo organizacional do que no campo pessoal.

\section{METODOLOGIA}

Esta pesquisa utiliza-se de uma abordagem hipotético-dedutiva, pois avança no sentido de testar e comprovar hipóteses, a partir de um suporte teórico, ao analisar os resultados obtidos (Theóphilo \& Martins, 2009). Trata-se de uma pesquisa aplicada na medida em que busca a geração de conhecimento para aplicação prática, investigando problemas reais (McBride, 2012) e caracteriza-se como descritiva ao descrever as características de uma população e ao estabelecer relações entre variáveis (Prodanov \& Freitas, 2013).

Em relação aos procedimentos adotados, classifica-se como experimento de campo, tendose variáveis dependente e explicativa, na qual o pesquisador interfere de modo a verificar essa influência (Prodanov \& Freitas, 2013).

\subsection{Procedimentos para coleta dos dados}

Para realizar um experimento são necessárias três condições: manipulação e controle das variáveis e distribuição aleatória dos participantes, de modo que tenham a mesma chance de participar dos diferentes grupos do experimento (de controle - decisões no campo pessoal- e experimental - decisões no campo organizacional) (Baptista \& Campos, 2016), e esta pesquisa atende essas condições. Em relação ao ambiente de aplicação, optou-se por um experimento de campo, que possui maior proximidade à realidade e, portanto, maior validade externa (Gray, 2012). O desenho da pesquisa contempla uma observação única após a manipulação da variável, para evitar vieses nas respostas dos gestores (Baptista \& Campos, 2016).

Diferentemente de diversos estudos à luz da Teoria do Prospecto que são realizados com amostras formados por alunos (Yoshinaga \& Ramalho, 2014), esta pesquisa foi aplicada a gestores de organizações vinculadas a Associações Comerciais e Industriais do Estado de Santa Catarina (Brasil). Delimitou-se o envio da pesquisa às associações dos dez municípios mais populosos, que somados abrigam aproximadamente $40 \%$ da população do Estado. Foi enviado e-mail apresentando a pesquisa, bem como realizado contato telefônico com essas associações, que aceitaram enviar e-mails aos seus associados. As associações receberam dois modelos do instrumento de pesquisa. Solicitou-se que enviassem aleatoriamente um modelo do instrumento à metade dos seus associados (grupo de controle) e outro modelo ao restante (grupo experimental).

A amostra compreende 236 gestores, que responderam à pesquisa. O nível de confiança é de $95 \%$, representando a probabilidade de se obter os mesmos resultados se outro grupo de indivíduos da mesma população fosse entrevistado. A margem de erro é de $6,4 \%$, que corresponde ao índice de variação dos resultados de uma pesquisa (Wooldridge, 2006). 
O instrumento de pesquisa foi dividido em dois blocos. O Bloco I contempla questões acerca das características demográficas dos gestores, que representam variáveis de controle e são coletadas e mensuradas em ambos os grupos (de controle e experimental), de modo a isolar o efeito da variável explicativa. As variáveis de controle foram definidas a partir de pesquisas que destacam sua influência sobre a tolerância ao risco dos gestores no momento da tomada de decisões. O Bloco I é idêntico para ambos os grupos. O Bloco II contempla questões acerca da tolerância ao risco dos gestores envolvendo perspectivas de ganhos e de perdas. Foi baseado principalmente em Kahneman e Tversky (1979), seguindo as mesmas proporções de probabilidades nas respostas às perguntas. No entanto, as situações foram adaptadas para os campos pessoal e organizacional. A Tabela 1 apresenta a estrutura do Bloco II para cada grupo.

Tabela 1. Estrutura do Bloco II do Instrumento de Pesquisa

\begin{tabular}{c|c|c|c|c}
\hline Grupo & Campo & Decisões & Perspectiva & Autores \\
\hline \multirow{2}{*}{ Controle } & Campo Pessoal & Decisões 01 a 10 & Ganhos & $\begin{array}{c}\text { Kahneman e Tversky (1979); Hsee e } \\
\text { Weber (1997); Reynolds, Joseph e } \\
\text { Sherwood (2009); Chakravarty et al. } \\
\text { (2011); Montinari e Rancan (2013). }\end{array}$ \\
\cline { 3 - 5 } Experimental & Campo Organi- & Decisões 11 a 20 & Perdas & $\begin{array}{c}\text { Kahneman e Tversky (1979); } \\
\text { Kahneman et al. (1990); Hsee e Weber } \\
\text { (1997). }\end{array}$ \\
& zacional & Decisões 01 a 10 & Ganhos & $\begin{array}{c}\text { Kahneman et al. (1990); Hsee e Weber } \\
\text { (1997); Reynolds, Joseph e Sherwood } \\
\text { (2009); Montinari e Rancan (2013). }\end{array}$ \\
\cline { 2 - 5 } & Decisões 11 a 20 & Perdas & $\begin{array}{c}\text { Kahneman e Tversky (1979); } \\
\text { Kahneman et al. (1990); Hsee e Weber } \\
\text { (1997). }\end{array}$ \\
\hline
\end{tabular}

Fonte: Elaborado pelos autores.

A Tabela 2 evidencia as variáveis da pesquisa, apresentando as siglas e descrições, com a categoria dessas variáveis e seus respectivos embasamentos teóricos.

Tabela 2. Embasamento das variáveis

\begin{tabular}{|c|c|c|c|c|}
\hline Sigla & Variável & Categoria & Autores & Métricas \\
\hline TR & $\begin{array}{c}\text { Tolerância ao } \\
\text { risco }\end{array}$ & Dependente & $\begin{array}{l}\text { (Kahneman \& Tversky, 1979; Hsee \& } \\
\text { Weber, 1997; Vlaev, Stewart \& Chater } \\
\text { 2008; Geetha \& Selvakumar, 2016) }\end{array}$ & $\begin{array}{l}\text { Variável Dicotômica } \\
0 \text { - Mais tolerante } \\
1 \text { - Menos tolerante }\end{array}$ \\
\hline CAM & $\begin{array}{l}\text { Campo no } \\
\text { qual a deci- } \\
\text { são está sen- } \\
\text { do tomada }\end{array}$ & Explicativa & $\begin{array}{l}\text { (Sinha, 1994; Eriksen \& Kvaløy, 2009; } \\
\text { Andersson et al., 2014; Kvaløy \& } \\
\text { Luzuriaga, 2014; Pahlke, Strasser \& } \\
\text { Vieider, 2015; He \& Villeval, 2017; } \\
\text { Schultz et al., 2018) }\end{array}$ & $\begin{array}{c}\text { Variável Dicotômica } \\
\text { 0 - Pessoal } \\
\text { 1- Organizacional }\end{array}$ \\
\hline IDA & Idade & Controle & $\begin{array}{c}\text { (Hallahan, Faff \& McKenzie, 2004; } \\
\text { Dohmen et al., 2011; Yao, Sharpe \& } \\
\text { Wang, 2011; Ross, Nora \& Milani, 2015; }\end{array}$ & $\begin{array}{l}\text { Quantitativa Discreta } \\
\qquad 0-99\end{array}$ \\
\hline
\end{tabular}




\begin{tabular}{|c|c|c|c|c|}
\hline & & & $\begin{array}{l}\text { Ramiah et al., 2016; Geetha \& } \\
\text { Selvakumar, 2016; Brooks et al., 2018) }\end{array}$ & \\
\hline GEN & Gênero & Controle & $\begin{array}{l}\text { (Grable, 2000; Dohmen et al., 2011; Yao, } \\
\text { Sharpe \& Wang, 2011; Montinari \& } \\
\text { Rancan, 2013; Ramiah et al., 2016; Geetha } \\
\text { \& Selvakumar, 2016; Brooks et al., 2018) }\end{array}$ & $\begin{array}{l}\text { Variável Dicotômica } \\
0 \text { - Masculino } \\
1 \text { - Feminino }\end{array}$ \\
\hline CIV & Estado civil & Controle & $\begin{array}{c}\text { (Hallahan, Faff \& McKenzie, 2004; Yao, } \\
\text { Sharpe \& Wang, 2011; Geetha \& } \\
\text { Selvakumar, 2016) }\end{array}$ & $\begin{array}{l}\text { Variável Dicotômica } \\
\text { 0 - Solteiro } \\
1 \text { - Não solteiro }\end{array}$ \\
\hline GIN & $\begin{array}{l}\text { Grau de } \\
\text { instrução }\end{array}$ & Controle & $\begin{array}{l}\text { (Sung \& Hanna, 1996; Grable \& Joo, 2004; } \\
\text { Hallahan, Faff \& McKenzie, 2004; Geetha } \\
\text { \& Selvakumar, 2016) }\end{array}$ & $\begin{array}{c}\text { Variável Politômica } \\
0 \text { - Ensino Fundamental } \\
1 \text { - Ensino Médio } \\
2 \text { - Curso Técnico } \\
3 \text { - Graduação } \\
4 \text { - Especialização } \\
5 \text { - Mestrado } \\
6 \text { - Doutorado }\end{array}$ \\
\hline FRM & $\begin{array}{l}\text { Faixa de } \\
\text { renda mensal }\end{array}$ & Controle & $\begin{array}{l}\text { (Sung \& Hanna, 1996; Grable, 2000; Gra- } \\
\text { ble \& Joo, 2004; Yao, Sharpe \& Wang, } \\
\text { 2011; Geetha \& Selvakumar, 2016; Brooks } \\
\text { et al., 2018) }\end{array}$ & $\begin{array}{c}\text { Variável Politômica } \\
0 \text { - Até } R \$ 1.908,00 \\
1 \text { - Mais de } R \$ 1.908,00 \text { até } R \$ \\
3.816,00 \\
2 \text { - Mais de } R \$ 3.816,00 \text { até } R \$ \\
9.540,00 \\
3 \text { - Mais de } R \$ 9.540,00 \text { até } R \$ \\
19.080,00 \\
4 \text { - Mais de } R \$ 19.080,00\end{array}$ \\
\hline FFA & $\begin{array}{l}\text { Faixa de } \\
\text { faturamento } \\
\text { anual da } \\
\text { organização }\end{array}$ & Controle & $\begin{array}{c}\text { (Ramiah et al., 2016; Geetha \& } \\
\text { Selvakumar, 2016) }\end{array}$ & $\begin{array}{c}\text { Variável Politômica } \\
0 \text { - Até } \mathrm{R} \$ 81.000,00 \\
1 \text { - De } \mathrm{R} \$ 81.000,01 \text { a } \mathrm{R} \$ \\
360.000,00 \\
2 \text { - De } \mathrm{R} \$ 360.000,01 \text { a } \mathrm{R} \$ \\
4.800 .000,00 \\
3 \text { - Acima de } \mathrm{R} \$ 4.800 .000,00\end{array}$ \\
\hline VRO & $\begin{array}{l}\text { Vínculo do } \\
\text { respondente } \\
\text { com a orga- } \\
\text { nização }\end{array}$ & Controle & (Rocha et al., 2018). & $\begin{array}{l}\text { Variável Dicotômica } \\
0 \text { - Proprietário }\end{array}$ \\
\hline
\end{tabular}




\begin{tabular}{|c|c|c|c|c|}
\hline & & & & 1 - Funcionário \\
\hline EXI & $\begin{array}{l}\text { Existência da } \\
\text { organização } \\
\text { (em anos) }\end{array}$ & Controle & $\begin{array}{c}\text { (Ramiah et al., 2016; Geetha \& } \\
\text { Selvakumar, 2016) }\end{array}$ & $\begin{array}{l}\text { Quantitativa Discreta } \\
\qquad 0-99\end{array}$ \\
\hline FUN & $\begin{array}{l}\text { Número de } \\
\text { funcionários }\end{array}$ & Controle & $\begin{array}{c}\text { (Ramiah et al., 2016; Geetha \& } \\
\text { Selvakumar, 2016) }\end{array}$ & $\begin{array}{c}\text { Variável Politômica } \\
0 \text { - Até } 9 \text { funcionários } \\
1 \text { - De } 10 \text { a } 99 \text { funcionários } \\
2 \text { - De } 100 \text { a } 999 \text { funcionários } \\
3 \text { - Acima de } 1.000 \text { funcioná- } \\
\text { rios }\end{array}$ \\
\hline EXP & $\begin{array}{l}\text { Experiência } \\
\text { do gestor (em } \\
\text { anos) }\end{array}$ & Controle & $\begin{array}{l}\text { (Shepherd, Williams \& Patzelt., 2015; } \\
\text { Ross, Nora \& Milani, 2015) }\end{array}$ & $\begin{array}{l}\text { Quantitativa Discreta } \\
\qquad 0-99\end{array}$ \\
\hline DEP & $\begin{array}{l}\text { Número de } \\
\text { dependentes }\end{array}$ & Controle & (Yao, Sharpe \& Wang, 2011) & $\begin{array}{l}\text { Quantitativa Discreta } \\
\qquad 0-99\end{array}$ \\
\hline PCP & $\begin{array}{c}\text { Percepção de } \\
\text { condição } \\
\text { financeira } \\
\text { própria }\end{array}$ & Controle & $\begin{array}{l}\text { (Viscusi, Magat \& Huber, 1987; Camerer, } \\
\text { 2005) }\end{array}$ & $\begin{array}{c}\text { Variável Politômica } \\
0 \text { - Muito endividado } \\
1 \text { - Pouco endividado } \\
2 \text { - Financeiramente equilibra- } \\
\text { do } \\
3 \text { - Financeiramente equilibra- } \\
\text { do com sobras e/ou aplica- } \\
\text { ções/investimentos }\end{array}$ \\
\hline $\mathrm{PCO}$ & $\begin{array}{l}\text { Percepção de } \\
\text { condição } \\
\text { financeira da } \\
\text { organização }\end{array}$ & Controle & $\begin{array}{l}\text { (Viscusi, Magat \& Huber, 1987; Camerer, } \\
\text { 2005) }\end{array}$ & $\begin{array}{c}\text { Variável Politômica } \\
0 \text { - Muito endividada } \\
1 \text { - Pouco endividada } \\
2 \text { - Financeiramente equilibra- } \\
\text { da } \\
3 \text { - Financeiramente equilibra- } \\
\text { da com sobras e/ou aplica- } \\
\text { ções/investimentos }\end{array}$ \\
\hline
\end{tabular}

Fonte: Elaborado pelos autores.

As vinte questões (situações de decisão) do Bloco II do instrumento de pesquisa no campo pessoal e do instrumento de pesquisa no campo organizacional foram elaboradas pelos autores da pesquisa. As probabilidades e montantes das alternativas são os mesmos apresentados por Kahneman e Tversky (1979). As situações decisionais, tanto no campo pessoal quanto no organizacional, estão embasados na literatura.

Aplicou-se pré-teste do questionário com dez gestores que não compuseram a amostra. Foram identificados alguns ajustes necessários ao instrumento de pesquisa, de modo a torna-lo mais claro e objetivo, reduzindo a possibilidade de distorções das decisões que compunham os instru- 
mentos de pesquisa. Foram ajustadas perguntas apontadas com interpretação dúbia e simplificadas situações que não foram bem compreendidas pelos gestores, no pré-teste.

O tempo médio de resposta foi de 25 minutos. No intuito de evitar possível diferença de atenção por parte dos gestores no momento da coleta de dados, em relação às ultimas questões, tomou-se o cuidado de que as decisões fossem apresentadas de forma aleatória aos participantes, os quais foram informados de que se tratava de uma pesquisa sobre tolerância ao risco, desenvolvida em um programa de pós-graduação em contabilidade. Foram informados também de que os dados não seriam divulgados de maneira individual, bem como não existiam respostas corretas ou incorretas. Os participantes também foram informados de que poderiam optar por desistir da pesquisa a qualquer momento, bastando desconsiderar o instrumento de pesquisa.

Dos 236 respondentes da pesquisa, 120 participaram do grupo de controle, em que tomaram decisões no campo pessoal, e 116 participaram do grupo experimental, em que tomaram decisões no campo organizacional. O período de coleta foi de setembro a novembro de 2018. Do total da amostra, 121 gestores se declararam do gênero masculino e 115 do gênero feminino. O grupo de controle teve o mesmo número de gestores do gênero masculino e feminino, enquanto o grupo experimental foi composto por $53 \%$ de gestores do gênero masculino e $47 \%$ do gênero feminino. A idade média dos respondentes é de 39 anos, sendo 37 anos a idade média do grupo de controle e 41 anos do grupo experimental. A maior parte dos gestores, 57\%, informou que possui pósgraduação (especialização, mestrado ou doutorado). Em relação à renda, 59\% informaram que têm renda mensal acima de 4 salários mínimos.

\subsection{Procedimentos para análise dos dados}

Os dados foram analisados quantitativamente por meio de regressão logística, buscando conhecer a relação entre variáveis a partir de uma variável dicotômica (binária), o que permitiu estimar a probabilidade da variável dependente - tolerância ao risco -, assumir determinados valores em função de outras variáveis (Wooldridge, 2006).

Realizou-se teste para a multicolinearidade dos dados visando identificar eventuais problemas no ajuste do modelo que poderiam causar impactos na estimativa dos parâmetros. Procedeu-se o Teste de Fator de Inflação da Variância (FIV), que permitiu identificar se alguma das variáveis inclusas no modelo estava causando uma inflação de variância, em decorrência de ser altamente correlacionada com outra variável, o que implicaria em multicolinearidade. A partir da realização do Teste FIV nos dados desta pesquisa, encontrou-se valores entre 1 e 2,8, não constatando problemas de multicolinearidade entre as variáveis. Wooldridge (2006) considera 10 como o valor de corte, afirmando que acima de 10 os dados apresentam problemas de multicolinearidade.

Realizou-se também o teste de comparação de modelos (um modelo sem as variáveis de controle e outro com as variáveis de controle apresentadas na literatura), e observou-se que o modelo que contemplava todas as variáveis de controle era o mais adequado, considerando os cenários nos quais seriam aplicadas as regressões. Assim, foi possível testar as hipóteses, a partir do Modelo 1, no qual estão contempladas as variáveis dependente, explicativa e de controle.

Modelo 1:

$$
\begin{gathered}
T R=\beta_{0}+\beta_{1} C A M+\beta_{2} I D A+\beta_{3} G E N+\beta_{4} C I V+\beta_{5} G I N+\beta_{6} F R M+\beta_{7} F F A+\beta_{8} V R O+\beta_{9} E X I \\
+\beta_{10} F U N+\beta_{11} E X P+\beta_{12} D E P+\beta_{13} P C P+\beta_{14} P C O+\varepsilon
\end{gathered}
$$

Partindo das bases teóricas e hipóteses desta pesquisa, utilizando-se dos procedimentos metodológicos descritos para coletar e analisar os dados, a próxima seção apresenta os resultados. 


\section{RESULTADOS DA PESQUISA}

\subsection{Tolerância ao risco no campo pessoal e organizacional}

As primeiras 10 decisões do Bloco II de ambos os grupos, apresentadas aos gestores, envolviam perspectiva de ganhos. Os gestores poderiam escolher entre a primeira alternativa, que contemplava um ganho maior com uma menor probabilidade de ocorrência, e uma segunda alternativa, na qual o ganho era menor, mas certo ou com maior probabilidade de ocorrência. A escolha da primeira alternativa classificava o gestor como mais tolerante ao risco, visto que se dispôs a assumir maior risco, e a escolha da segunda alternativa o classificava como menos tolerante, visto que mesmo diante de um ganho menor, preferiu este por ser garantido ou com probabilidade maior do que na primeira alternativa.

As decisões de número 11 a 20 tratavam de decisões que envolviam perspectiva de perdas. As escolhas entre as alternativas refletiam a mesma classificação das dez primeiras decisões, com as mesmas probabilidades e montantes, conforme o efeito reflexo apresentado por Kahneman e Tversky (1979).

A Figura 2 representa as respostas dos 236 gestores, indicando o percentual de gestores menos tolerantes ao risco em cada uma das decisões. Para cada uma das 20 decisões são apresentadas duas barras, indicando o percentual de gestores menos tolerantes ao risco nos campos pessoal e organizacional em cada decisão. A coluna pode ir de $0 \%$, quando ninguém optou pela alternativa menos tolerante, até $100 \%$, quando todos optaram pela alternativa menos tolerante.

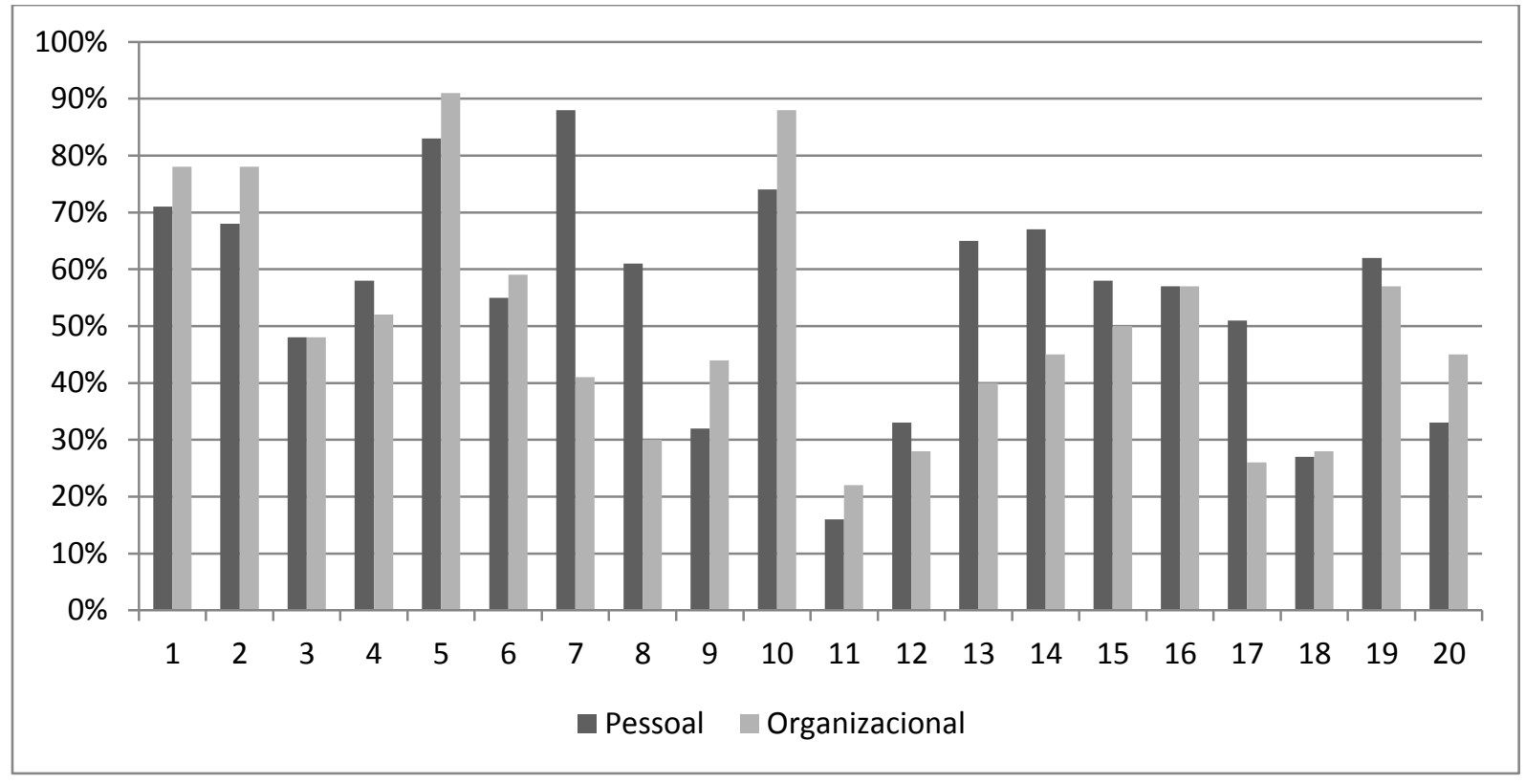

Figura 2. Percentual de gestores menos tolerantes ao risco

Fonte: Elaborado pelos autores.

É possível observar que nas primeiras 10 decisões, na perspectiva de ganhos, os gestores de ambos os grupos são menos tolerantes ao risco quando comparado com o comportamento nas decisões de 11 a 20, que envolviam a perspectiva de perdas. Esse resultado corrobora a literatura quando esta afirma que os indivíduos são menos tolerantes ao risco na perspectiva de ganhos e mais tolerantes na perspectiva de perdas (Kahneman \& Tversky, 1979; Tversky \& Kahneman, 1991; Scholten \& Read, 2014).

Comparando as respostas entre os grupos, neste estudo ficou latente a existência de diferença na tolerância ao risco dos gestores nos contextos pessoal e organizacional. Na maioria das decisões de 1 a 10 (perspectiva de ganhos), os gestores se posicionaram de forma menos tolerante 
ao risco diante de decisões organizacionais, indicando que são menos tolerantes ao risco no campo organizacional do que no campo pessoal. Analisando os percentuais de respostas das decisões de 11 a 20 (perspectiva de perdas), observa-se o contrário, ou seja, na perspectiva de perdas os gestores apresentaram comportamento menos tolerante ao risco nas decisões pessoais do que nas organizacionais.

Em algumas decisões que envolviam ganhos, como nas decisões 3, 7, 8 e 9, os resultados indicam que a maior parte dos gestores se comportou de forma mais tolerante ao risco, diferentemente do que propõe a Teoria do Prospecto. No entanto, essa diferença foi pequena, com exceção da decisão 8 , em que $70 \%$ dos gestores foram mais tolerantes ao risco.

Em relação às decisões na perspectiva de perdas, apenas nas decisões 16 e 19 não se observou convergência com a Teoria do Prospecto, sendo que a maioria dos gestores se comportou de forma menos tolerante ao risco, contrariando a teoria. Essa maioria de gestores menos tolerante foi de $57 \%$, de modo que $43 \%$ dos gestores se comportaram conforme descrito pela TP também nas decisões 16 e 19.

Realizou-se também análises, a partir de regressão logística, adotando um modelo com tolerância ao risco como variável dependente, o campo da decisão como variável explicativa, e características dos gestores e das organizações como variáveis de controle. Aos questionários com decisões do campo pessoal atribuiu-se " 0 " à variável campo de decisão, e aos questionários com decisões do campo organizacional atribuiu-se "1". Os resultados obtidos por meio do software R Studio são apresentados na Tabela 3.

Tabela 3. Regressão logística

Decisões na perspectiva de ganhos

\begin{tabular}{l|c|c|c|c|c|c|c|c|c|c|c}
\hline Decisão & 1 & 2 & 3 & 4 & 5 & 6 & 7 & 8 & 9 & 10 \\
\hline Coeficiente & 0.368 & $0.573^{*}$ & 0.115 & -0.233 & $0.996^{* *}$ & 0.202 & $-2.714^{* * *}$ & $-1.344^{* * *}$ & 0.492 & $1.137^{* * *}$ \\
\hline \multicolumn{7}{|c|}{ Decisões na perspectiva de perdas } \\
\hline Decisão & 11 & 12 & 13 & 14 & 15 & 16 & 17 & 18 & 19 & 20 \\
\hline Coeficiente & 0.632 & -0.402 & $-1.005^{* * *}$ & $-0.843^{* * *}$ & -0.428 & 0.053 & $-1.210^{* * *}$ & 0.083 & -0.092 & 0.375 \\
\hline
\end{tabular}

Nota. *significância ao nível de $10 \%$; ** significância ao nível de 5\%, e; ${ }^{* * *}$ significância ao nível de $1 \%$.

Fonte: Elaborado pelos autores.

Os coeficientes apresentados nos resultados da regressão logística não representam as variações de chance, sendo necessário calcular a exponencial de cada coeficiente significante para se saber a influência de cada variável. Esses percentuais são apresentados na Tabela 4. 
Tabela 4. Variações de chances

Decisões na perspectiva de ganhos

\begin{tabular}{l|c|c|c|c|c|c|c|c|c|c|c}
\hline Decisão & 1 & 2 & 3 & 4 & 5 & 6 & 7 & 8 & 9 & 10 \\
\hline $\begin{array}{l}\text { Variação de } \\
\text { Chance }\end{array}$ & & $77 \%$ & & & $171 \%$ & & $-93 \%$ & $-74 \%$ & & $212 \%$ \\
\hline \begin{tabular}{l} 
Decisão \\
\hline $\begin{array}{l}\text { Variação de } \\
\text { Chance }\end{array}$
\end{tabular} & 11 & 12 & 13 & 14 & 15 & 16 & 17 & 18 & 19 & 20 \\
\hline
\end{tabular}

Fonte: Elaborado pelos autores.

Nas decisões na perspectiva de ganhos, os resultados indicam que o campo de decisão foi significante na determinação da tolerância ao risco dos gestores em cinco das dez decisões analisadas. Essa significância foi identificada nas decisões 2, 5, 7, 8 e 10. Nas decisões 7 e 8, gestores que tomaram decisões no campo organizacional apresentaram maior tendência (variações de chance de $93 \%$ e $74 \%$ respectivamente) de optar pela alternativa mais tolerante ao risco, quando comparados com os gestores que decidiram no campo pessoal.

Ainda na perspectiva de ganhos, nas decisões 2, 5 e 10, os gestores do campo organizacional apresentaram chance $77 \%, 171 \%$ e $212 \%$ maior, respectivamente, de optar pela alternativa menos tolerante, quando comparados com os gestores que decidiram no campo pessoal. Ou seja, nesses casos, o fato da decisão ser no campo organizacional aumentou a chance de os gestores apresentarem comportamento menos tolerante ao risco.

Nas decisões que envolviam perdas, os resultados indicam que os gestores que tomaram decisões no campo organizacional apresentaram maior tolerância ao risco nas decisões 13, 14 e 17, apresentando chance $63 \%$, 57\% e 70\% maior, respectivamente, de optar pela alternativa mais tolerante ao risco, quando comparados com gestores que tomaram decisões no campo pessoal.

Esses resultados indicam que o campo no qual se está tomando a decisão influencia na tolerância ao risco do decisor, mais especificamente, no caso deste estudo, na tolerância ao risco dos gestores. Esta influência é defendida por Sinha, 1994; Eriksen \& Kvaløy, 2009; Andersson et al., 2014; Kvaløy \& Luzuriaga, 2014; Pahlke, Strasser \& Vieider, 2015; He \& Villeval, 2017; Schultz et al., 2018, que destacam que as pessoas mudam sua tolerância ao risco quando muda o campo de decisão (Reynolds, Joseph \& Sherwood, 2009).

Em relação às variáveis de controle, ao analisar apenas as decisões que envolviam perspectiva de ganhos, também foram encontrados resultados estatisticamente significantes. Esses resultados indicam que a idade apresenta influência na tolerância ao risco, de modo que quanto maior a idade dos gestores, maior a sua tolerância ao risco. Verificou-se também que indivíduos do gênero feminino são menos tolerantes ao risco do que os do gênero masculino. Ainda em situações envolvendo ganhos, verificou-se que indivíduos não solteiros podem apresentar menor tolerância ao risco do que os solteiros em decisões de ganhos e que quanto maior o número de funcionários da organização, mais tolerância apresentaram os gestores dessas organizações. Observou-se também que quanto maior a experiência, mais tolerantes ao risco são os gestores. As variáveis grau de instrução e a percepção da condição financeira própria apresentaram influência sobre tolerância ao risco, mas com resultados divergentes em diferentes situações.

Já em decisões que envolviam perspectivas de perdas, as variáveis idade e gênero não apresentaram significância estatística em nenhuma das decisões apresentadas. Ainda em situações de perdas, os resultados indicam também que quanto maior a renda do gestor, maior a tendência de o 
mesmo ser menos tolerante ao risco e que gestores funcionários das organizações são mais tolerantes ao risco do que quando são proprietários. A percepção de uma boa condição financeira da organização determinou um comportamento mais tolerante dos gestores, indicando uma preferência em optar por perdas maiores, mas menos prováveis. Já as variáveis estado civil e tempo de existência da organização apresentaram influência sobre a tolerância ao risco, em decisões que envolviam perdas, mas com resultados divergentes nas diferentes situações apresentadas.

\subsection{Discussão dos resultados}

Os resultados deste estudo indicam que os gestores apresentam menor tolerância ao risco em situações envolvendo ganhos do que perdas. Esse resultado acompanha e apoia a literatura, a qual afirma que indivíduos são avessos ao risco no ganho e o procuram diante de perdas (Kahneman \& Tversky, 1979; Kahneman, Knetsch \& Thaler, 1990; Tversky \& Kahneman, 1991; Zaleskiewicz, 2001; Abdellaoui, Bleichrodt \& Kammoun, 2013; Talpsepp, Vlcek \& Wan, 2014).

As hipóteses foram analisadas a partir do Modelo 1, testado e estimado a partir dos dados coletados. A Tabela 5 apresenta os sinais esperados e os encontrados para cada hipótese e decisão do estudo que apresentou significância estatística.

\section{Tabela 5. Sinais encontrados para as hipóteses de pesquisa}

\begin{tabular}{|c|c|c|c|c|c|c|c|c|c|c|c|}
\hline \multirow{2}{*}{ Hipótese } & \multirow{2}{*}{$\begin{array}{c}\text { Sinal } \\
\text { esperado }\end{array}$} & \multicolumn{10}{|c|}{$\begin{array}{l}\text { Sinal encontrado nas decisões na perspectiva de } \\
\text { ganhos }\end{array}$} \\
\hline & & 1 & 2 & 3 & 4 & 5 & 6 & 7 & 8 & 9 & 10 \\
\hline $\begin{array}{l}\text { H1: Na perspectiva de ganhos, os gestores são } \\
\text { menos tolerantes ao risco na tomada de deci- } \\
\text { sões no campo organizacional do que no campo } \\
\text { pessoal. }\end{array}$ & + & & + & & & + & & - & - & & + \\
\hline \multirow[t]{2}{*}{ Hipótese } & \multirow[t]{2}{*}{$\begin{array}{c}\text { Sinal } \\
\text { esperado }\end{array}$} & \multicolumn{10}{|c|}{$\begin{array}{l}\text { Sinal encontrado nas decisões na perspectiva de } \\
\text { perdas }\end{array}$} \\
\hline & & 11 & 12 & 13 & 14 & 15 & 16 & 17 & 18 & 19 & 20 \\
\hline $\begin{array}{l}\text { H2: Na perspectiva de perdas, os gestores são } \\
\text { mais tolerantes ao risco na tomada de decisões } \\
\text { no campo organizacional do que no campo } \\
\text { pessoal. }\end{array}$ & - & & & - & - & & & - & & & \\
\hline
\end{tabular}

Fonte: Elaborado pelos autores.

O comportamento esperado na hipótese H1 foi identificado nas decisões 2, 5 e 10, indicando que na perspectiva de ganhos os gestores são menos tolerantes ao risco quando decidem no campo organizacional do que no pessoal. Já nas decisões 7 e 8 , observou-se influência do campo de decisão sobre a tolerância ao risco, mas em sentido contrário ao esperado na hipótese H1, indicando que, nesses casos, os gestores se comportaram de forma mais tolerante ao risco nas decisões do campo organizacional do que no pessoal.

O comportamento esperado na hipótese H2 foi identificado nas decisões 13, 14 e 17, indicando que na perspectiva de perdas, os gestores são mais tolerantes ao risco quando decidem no campo organizacional do que no pessoal. Não houve situações com comportamento contrário ao esperado no campo das perdas.

Kahneman e Tversky (1979) e Tversky e Kahneman (1991) afirmam que na perspectiva de ganhos os indivíduos são menos tolerantes ao risco. Os achados desta pesquisa corroboram e indi- 
cam, complementarmente, que quando se comparam decisões pessoais com decisões organizacionais, esse comportamento de não tolerância ao risco pode variar, dependendo do campo no qual se está tomando a decisão.

Quando as situações envolviam perdas, encontrou-se significância estatística em um terço das decisões, quando os gestores foram mais tolerantes ao risco em decisões organizacionais do que em pessoais. De acordo com a literatura (Kahneman \& Tversky, 1979; Tversky \& Kahneman, 1991), na perspectiva de perdas os indivíduos são mais tolerantes ao risco do que na de ganhos. Essa pesquisa corrobora e indica ainda que quando se comparam decisões pessoais com decisões organizacionais, ambas envolvendo situações de perdas, em decisões organizacionais os gestores são mais tolerantes do que em decisões pessoais.

A Figura 3 apresenta uma projeção da tolerância ao risco dos indivíduos no campo organizacional, comparando com os resultados de Kahneman e Tversky (1979), que embasaram este estudo, quando analisaram a tolerância ao risco dos indivíduos em situações de decisões pessoais.

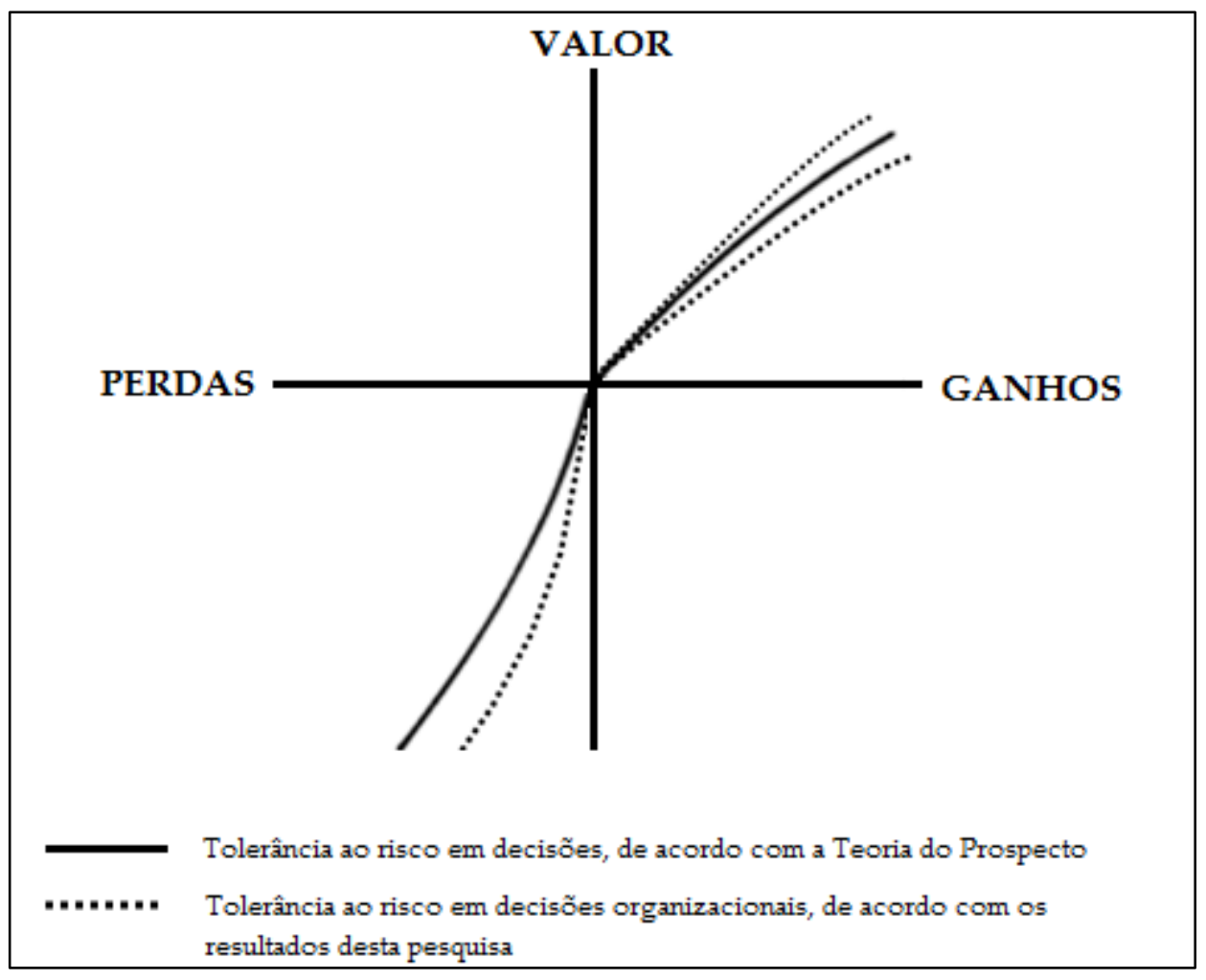

Figura 3. Tolerância ao risco no campo organizacional

Fonte: Elaborado pelos autores.

Na Figura 3, considerando que Kahneman e Tversky (1979) analisaram as decisões em contextos pessoais, considera-se o gráfico original como as decisões pessoais e as projeções em pontilhado como decisões organizacionais.

Uma das hipóteses deste estudo (H1) pressupôs que, na perspectiva de ganhos, os gestores são menos tolerantes ao risco em decisões organizacionais do que em pessoais, o que foi identificado em duas decisões. Assim, na Figura 3, projetou-se duas pontilhadas, uma mais próxima e outra mais distante do eixo $\mathrm{x}$, indicando menor tolerância ao risco em alguns casos, e maior noutros, quando os gestores tomam decisões organizacionais em relação às decisões pessoais.

A segunda hipótese da pesquisa (H2) afirmava que na perspectiva de perdas os gestores são mais tolerantes ao risco em decisões organizacionais do que em pessoais. Na Figura 3, a linha pontilhada que indica a tolerância ao risco no campo organizacional se afasta mais do eixo $x$, indi- 
cando maior tolerância ao risco dos gestores, em situações de perdas, quando tomam decisões organizacionais em relação às decisões pessoais. Esse comportamento foi observado em três situações com as quais os gestores foram confrontados.

Em relação às demais variáveis, a literatura apresenta que a tolerância ao rico diminui com o aumento da idade dos indivíduos (Hallahan, Faff \& McKenzie, 2004; Dohmen et al., 2011; Ross, Nora \& Milani, 2015; Ramiah et al., 2016; Geetha \& Selvakumar, 2016; Brooks et al., 2018), diferentemente do resultado encontrado neste estudo, no qual a idade apresentou influência na tolerância ao risco em situações de ganhos - indicando que quanto maior a idade dos gestores, maior a sua tolerância ao risco - e não apresentou significância em situações de perdas.

Quanto ao gênero, os resultados em perspectiva de ganhos corroboram a literatura, a qual indica que indivíduos do gênero feminino são menos tolerantes ao risco do que os indivíduos do gênero masculino (Grable, 2000; Dohmen et al., 2011; Yao, Sharpe \& Wang, 2011; Montinari \& Rancan, 2013; Francis et al., 2015; Ramiah et al., 2016; Geetha \& Selvakumar, 2016; Brooks et al., 2018). Em situações de perdas não se encontrou influência.

Os resultados acerca do estado civil também corroboram a literatura em situações de ganhos, visto que os indivíduos solteiros foram mais tolerantes ao risco (Hallahan, Faff \& McKenzie, 2004; Yao, Sharpe \& Wang, 2011; Geetha \& Selvakumar, 2016). Nas situações envolvendo perdas, os resultados foram ambíguos.

Esses achados ampliam os conhecimentos acerca da influência do campo de decisão sobre a tolerância ao risco, indicando que há essa influência e em qual sentido ela ocorre. Desse modo, os resultados contribuem com a literatura apontando o campo no qual se tomam as decisões como fato que influencia na tolerância ao risco, de modo que estudos possam se aprofundar nessa questão de pesquisa.

Contribui ainda gerencialmente com as organizações fornecendo indícios de comportamento dosa gestores específicos quando tomam decisões na organização, diferindo da tolerância ao risco apresentada quando tomam decisões pessoais.

\section{CONCLUSÕES E RECOMENDAÇÕES}

Considerando que os estudos comportamentais envolvendo tolerância ao risco se concentram mais em decisões pessoais, neste estudo buscou-se analisar se o campo da decisão (pessoal ou organizacional) influencia na tolerância ao risco de gestores. Para tanto, isolou-se o campo no qual a decisão foi tomada, tornando-o uma variável de estudo e realizou-se comparações do comportamento com situações semelhantes, mas em campos de decisão diferentes. Além disso, por acreditar que há outros fatores que influenciam na tomada de decisão, incorporou-se no estudo características pessoais e/ou organizacionais.

Diferentemente do que ocorre nas decisões pessoais, nas organizacionais é comum que a pessoa decida em nome e com os recursos de outras pessoas e, nessa situação, busque representar a tolerância ao risco do terceiro para o qual está tomando a decisão. Assim, neste estudo optou-se por pesquisar a tolerância ao risco de gestores nos campos pessoal e organizacional, visto que correspondem aos indivíduos que tomam decisões pessoais, assim como quaisquer outros indivíduos, e ao mesmo tempo se deparam com situações que envolvem decisões organizacionais.

Os resultados indicam que o campo em que a decisão é tomada influencia na tolerância ao risco do decisor. Isso se verificou mesmo diante de alternativas com montantes e probabilidades de ganhos ou perdas iguais. Ou seja, diferenciando o campo de decisão (pessoal ou organizacional), verificou-se comportamentos de tolerância ao risco diferentes por parte dos gestores, mesmo quando se tratavam de probabilidades e montantes idênticos.

A literatura apresenta e é amplamente aceito o entendimento de que os indivíduos são menos tolerantes ao risco em situações de ganhos do que em situações de perdas. Nesta pesquisa, 
identificou-se esse mesmo comportamento e, complementarmente, identificou-se que em decisões organizacionais esses comportamentos ocorrem de forma mais acentuada. Diante de situações de ganhos, na maioria dos casos estatisticamente significantes os gestores se comportaram de forma ainda menos tolerante ao risco nas decisões organizacionais, se comparadas a decisões pessoais. Quando confrontados com situações de perdas, apresentaram comportamento ainda mais tolerante ao risco nas decisões organizacionais do que nas decisões no campo pessoal.

Dessa forma, este estudo complementa a Teoria do Prospecto que descreve o comportando dos indivíduos diante de escolhas entre alternativas que envolvem riscos, ao evidenciar que em situações de perdas e nas organizações, os gestores são ainda mais tolerantes ao risco do que o indicado pela teoria; e em situações de ganhos, nas organizações, os gestores são ainda menos tolerantes ao risco do que o indicado pela teoria, na maioria dos casos significantes.

Esses achados correspondem a uma ampliação dos conhecimentos acerca dos estudos sobre tolerância ao risco, visto que apresentam o campo de decisão como mais um fator que influencia no comportamento dos gestores na tomada de decisão, indicando ainda qual o sentido para o qual o comportamento do gestor é direcionado, no que diz respeito à tolerância ao risco. Isto se constitui num fato novo e intrigante a ser investigado e discutido em estudos e discussões futuras.

Assim, este estudo contribui com a literatura, ao complementar o que apresenta a Teoria do Prospecto. Contribui ainda empiricamente ao propiciar às organizações maior compreensão dos fatores que influenciam o risco dos gestores e que eles podem decidir na organização de forma diferente do que decidem em situações particulares. Compreender os fatores que influenciam o risco e que o próprio ambiente organizacional consiste em um desses fatores permite que as organizações adotem estratégias que desenvolvam em seus gestores comportamento de maior ou menor tolerância ao risco nas decisões organizacionais alinhados com seus interesses.

Esta pesquisa apresenta limitações, dentre as quais estão possíveis vieses decorrentes de interpretação por parte dos gestores diante dos instrumentos de pesquisa. Também não são conhecidas e nem foram mensuradas todas as variáveis que podem influenciar a tolerância ao risco, tendo sido consideradas como variáveis de controle as abordadas na literatura. Os resultados encontrados, apesar de terem sido captados junto a pessoas que efetivamente vivenciam estas situações, foram observados em um grupo preexistente de gestores, de modo que se deve ter cautela com a generalização. A delimitação geográfica e as influências culturais das regiões pesquisadas também podem impactar na tolerância ao risco dos gestores. Por fim, o fato de o estudo ter sido desenvolvido junto a gestores em decisões individuais também pode ter repercussões, visto que as decisões em grupo ou coletivas podem diferir e apresentar comportamentos diferentes em função da pluralidade e características pessoais de cada um dos envolvidos.

Para estudos futuros recomenda-se a inserção de novas variáveis, a replicação com outros públicos ou, ainda, envolver decisões coletivas ou em grupo. A adoção de outros métodos de análise também pode trazer novos olhares sobre o tema ou reforçar os encontrados neste estudo.

\section{REFERÊNCIAS}

Abdellaoui, M., Bleichrodt, H., \& Kammoun, H. (2013). Do financial professionals behave according to prospect theory? An experimental study. Theory and Decision, 74(3), 411-429.

Andersson, O., Holm, H. J., Tyran, J. R., \& Wengström, E. (2014). Deciding for others reduces loss aversion. Management Science, 62(1), 29-36.

Baptista, M. N., Campos, D. C. (2016). Metodologias Pesquisa em Ciências: Análise Quantitativa e Qualitativa. Rio de Janeiro: LTC. 
Bilk, Â., Barbosa, E. T., da Silva, T. P., \& Nakamura, W. T. (2018). Aversão a Perda e Satisfação ao Ganho nos Aspectos Comportamentais dos Acadêmicos e Profissionais da Atuária. Caderno Profissional de Administração da UNIMEP, 8(1), 24-44.

Brooks, C., Sangiorgi, I., Hillenbrand, C., \& Money, K. (2018). Why are older investors less willing to take financial risks? International Review of Financial Analysis, 56, 52-72.

Camerer, C. (2005). Three cheers - psychological, theoretical, empirical-for loss aversion. Journal of Marketing Research, 42(2), 129-133.

Chakravarty, S., Harrison, G. W., Haruvy, E. E., \& Rutström, E. E. (2011). Are you risk averse over other people's money? Southern Economic Journal, 77(4), 901-913.

Chen, X., Sim, M., Simchi-Levi, D., \& Sun, P. (2007). Risk aversion in inventory management. Operations Research, 55(5), 828-842.

Dohmen, T., Falk, A., Huffman, D., Sunde, U., Schupp, J., \& Wagner, G. G. (2011). Individual risk attitudes: Measurement, determinants, and behavioral consequences. Journal of the European Economic Association, 9(3), 522-550.

Eriksen, K. W., \& Kvaløy, O. (2009). Myopic investment management. Review of Finance, 14(3), 521542.

Fagundes, E., Schnorrenberger, D., \& Lunkes, R. J. (2018). Aversão ao risco na tomada de decisões organizacionais: análise da literatura e oportunidades de pesquisa. Revista de Contabilidade do Mestrado em Ciências Contábeis da UERJ, 23(2), 19-36.

Gava, A. M., \& Vieira, K. M. (2008). Risco e gênero: medindo a tolerância ao risco e as diferenças entre os gêneros. Revista de Ciências da Administração, 10(20), 114-138.

Geetha, S. N., \& Selvakumar, M. M. (2016). An analysis on the factors influencing risk tolerance level of individual investors. International Journal of Business Excellence, 9(2), 253-264.

Grable, J. E. (2000). Financial risk tolerance and additional factors that affect risk taking in everyday money matters. Journal of Business and Psychology, 14(4), 625-630.

Grable, J. E., \& Joo, S. H. (2004). Environmental and biophysical factors associated with financial risk tolerance, Journal of Financial Counseling and Planning, 15(1), 73-82.

Gray, D. E. (2012). Pesquisa no mundo real. Porto Alegre: Penso Editora.

Hallahan, T. A., Faff, R. W., \& McKenzie, M. D. (2004). An empirical investigation of personal financial risk tolerance. Financial Services Review-Greenwich-, 13(1), 57-78.

Hammond, J. S., Keeney, R. L., \& Raiffa, H. (1998). The hidden traps in decision making. Harvard business review, 76(5), 47-58.

Hammond, J. S., Keeney, R., \& Raiffa, H. (1999). Somos movidos a decisões, decisões inteligentes: como avaliar alternativas e tomar a melhor decisão. Rio de Janeiro, Campus.

Hammond, J. S., Keeney, R. L., \& Raiffa, H. (2017). Decisões inteligentes: como avaliar alternativas $e$ tomar a melhor decisão. Alta Books Editora.

Harvey, N., Twyman, M., \& Harries, C. (2006). Making decisions for other people: the problem of judging acceptable levels of risk. In Forum Qualitative Sozialforschung/Forum: Qualitative Social Research, 7(1), Art. 26.

He, H., \& Villeval, M. C. (2017). Are group members less inequality averse than individual decision makers? Journal of Economic Behavior E Organization, 138, 111-124. 
Hsee, C. K., \& Weber, E. U. (1997). A fundamental prediction error: Self-others discrepancies in risk preference. Journal of experimental psychology: general, 126(1), 45.

Kahneman, D., Knetsch, J. L., \& Thaler, R. H. (1990). Experimental tests of the endowment effect and the Coase theorem. Journal of political Economy, 98(6), 1325-1348.

Kahneman, D. (2012). Rápido e devagar: duas formas de pensar. Tradução Cássio de Arantes Leite. Rio de Janeiro: Objetiva.

Kahneman, D., \& Tversky, A. (1979). Prospect Theory: An Analysis of Decisions under Risk. Econometrica, 47(2), 263-291.

Kvaløy, O., \& Luzuriaga, M. (2014). Playing the trust game with other people's money. Experimental Economics, 17(4), 615-630.

Leonard, N. H., Scholl, R. W., \& Kowalski, K. B. (1999). Information processing style and decision making. Journal of Organizational Behavior, 20(3), 407-420.

Lima Filho, R. N.; \& Bruni, A. L. (2013). Quanto mais faço, mais erro? Uma análise sobre a presença de vieses cognitivos em julgamentos sobre orçamento. Revista Base, 10(3), 224-239.

Lobel, R. E., Klotzle, M. C., Silva, P. V. J. G., \& Pinto, A. C. F. (2018). Teoria do Prospecto: fatores determinantes nas preferências ao risco no Brasil. Race: revista de administração, contabilidade e economia, 17(2), 535-566.

Lucena, I. F. O., Gomes, L. F. O., Ferreira, P. S., \& Lucena, W. G. L. (2011). Finanças Comportamentais: Um Estudo Com Profissionais Da Área Da Saúde Diante Da Aversão À Perda Financeira. Veredas Favip-Revista Eletrônica de Ciências, 4(1), 104-121.

Luppe, M. R.; \& Angelo, C. F. de. (2010). As decisões de consumo e a heurística da ancoragem: uma análise da racionalidade do processo de escolha. RAM- Revista de Administração Mackenzie, 11(6), 81-106.

McBride, D. M. (2012). The process of research in psychology. Los Angeles: Sage.

Melesse, M. B., \& Cecchi, F. (2017). Does Market Experience Attenuate Risk Aversion? Evidence from Landed Farm Households in Ethiopia. World Development, 98, 447-466.

Montinari, N., \& Rancan, M. (2013). Social preferences under risk: the role of social distance (No. 2013050). Jena Economic Research Papers, 1-34.

Nobre, L. H., Macedo, A. F. P., Nobre, F. C., \& Silva, W. V. (2017). Análise da relação entre variáveis demográficas e escores de tolerância ao risco. Revista de Administração da Universidade Federal de Santa Maria, 10(1), 116-128.

Oliveira, R. L., \& Krauter, E. (2015). Teoria do prospecto: como as finanças comportamentais podem explicar a tomada de decisão. Revista Pretexto, 16(3), 106-121.

Pahlke, J., Strasser, S., \& Vieider, F. M. (2015). Responsibility effects in decision making under risk. Journal of Risk and Uncertainty, 51(2), 125-146.

Prodanov, C. C., \& Freitas, E. C. de. (2013). Metodologia do Trabalho Científico: Métodos e Técnicas da Pesquisa e do Trabalho Acadêmico-2 ${ }^{a}$ Edição. Editora Feevale.

Ramiah, V., Zhao, Y., Moosa, I., \& Graham, M. (2016). A behavioural finance approach to working capital management. The European Journal of Finance, 22(8-9), 662-687. 
Reynolds, D. B., Joseph, J., \& Sherwood, R. (2009). Risky shift versus cautious shift: determining differences in risk taking between private and public management decision-making. Journal of Business and Economics Research, 7(1), 63-77.

Rocha, M. S., Albuquerque Filho, A. R., Freire, M. M. A., \& Ramos, S. V. (2018). O conhecimento e a aplicação do princípio da entidade pelos microempresários do setor comercial da cidade de Sobral-CE. Revista de Administração do Sul do Pará, 5(1).

Rodrigues, A. F. C., \& Veloso, A. L. D. O. M. (2013). Confiança organizacional, risco e criatividade. Revista Brasileira de Gestão de Negócios, 15(49), 545-561.

Ross, G. D., Nora, B. D., \& Milani, B. (2015). Aversão ao risco em profissionais do setor financeiro. Revista de Administração da Universidade Federal de Santa Maria, 8, 104-118.

Russo, J. E., \& Schoemaker, P. J. (2002). Decisões vencedoras. Trad Hugo Melo. Rio de Janeiro: Campus.

Salterio, S. E. (2015). Barriers to knowledge creation in management accounting research. Journal of Management Accounting Research, 27(1), 151-170.

Scholten, M., \& Read, D. (2014). Prospect theory and the "forgotten" fourfold pattern of risk preferences. Journal of Risk and Uncertainty, 48(1), 67-83.

Schultz, K. L., Robinson, L. W., Thomas, L. J., Schultz, J., \& McClain, J. O. (2018). The Use of Framing in Inventory Decisions. Production and Operations Management, 27(1), 49-57.

Shepherd, D. A., Williams, T. A., \& Patzelt, H. (2015). Thinking about entrepreneurial decision making: Review and research agenda. Journal of management, 41(1), 11-46.

Shields, M. D. (2015). Established management accounting knowledge. Journal of Management Accounting Research, 27(1), 123-132.

Simon, H. A., Dantzig, G. B., Hogarth, R., Plott, C. R., Raiffa, H., Schelling, T. C., ... \& Winter, S. (1987). Decision making and problem solving. Interfaces, 17(5), 11-31.

Sinha, T. (1994). Prospect theory and the risk return association: another look. Journal of Economic Behavior E Organization, 24(2), 225-231.

Solino, A. D. S., \& El-Aouar, W. A. (2010). O processo de tomada de decisões estratégicas: entre a intuição e a racionalidade. REGE Revista de Gestão, 8(3), 15-26.

Souza, M. L. (2017). Finanças comportamentais: um estudo das publicações no Enanpad no período de 2003 a 2013. Conhecimento Interativo, 11(1), 59-74.

Sung, J., \& Hanna, S. (1996). Factors related to risk tolerance. Journal of Financial Counseling and Planning, 7, 11-19.

Talpsepp, T., Vlcek, M., \& Wang, M. (2014). Speculating in gains, waiting in losses: A closer look at the disposition effect. Journal of Behavioral and Experimental Finance, 2, 31-43.

Theóphilo, C. R., \& Martins, G. D. A. (2009). Metodologia da investigação científica para ciências sociais aplicadas. São Paulo: Atlas, 2(104-119), 25.

Tversky, A., \& Kahneman, D. (1991). Loss aversion in riskless choice: A reference-dependent model. The quarterly journal of economics, 106(4), 1039-1061.

Viscusi, W. K., Magat, W. A., \& Huber, J. (1987). An investigation of the rationality of consumer valuations of multiple health risks. The RAND journal of economics, 465-479. 
Vlaev, I., Stewart, N., \& Chater, N. (2008). Risk preference discrepancy: A prospect relativity account of the discrepancy between risk preferences in laboratory gambles and real world investments. The Journal of Behavioral Finance, 9(3), 132-148.

Wooldridge, J. M. (2006). Introdução à econometria: uma abordagem moderna. Pioneira Thomson Learning.

Yao, R., Sharpe, D. L., \& Wang, F. (2011). Decomposing the age effect on risk tolerance. The Journal of Socio-Economics, 40(6), 879-887.

Yoshinaga, C. E., \& Ramalho, T. B. (2014). Finanças comportamentais no Brasil: uma aplicação da teoria da perspectiva em potenciais investidores. Revista Brasileira de Gestão de Negócios, 16(53), 594-615.

Zaleskiewicz, T. (2001). Beyond risk seeking and risk aversion: Personality and the dual nature of economic risk taking. European journal of Personality, 15(S1), 105-122. 